\title{
Zoometrical index analysis of Nigerian indigenous goat populations
} *Popoola, M. A. and Adekanbi, A. O.

Federal College of Animal Health and Production Technology, Ibadan, Nigeria

*Corresponding author: herbyolar@gmail.com

\section{Abstract}

The study was conducted to assess the zoometrical index analyses of Nigerian indigenous breeds of goats. The sampled populations of goat included 100 from each of three populations of goat in Nigeria; Red Sokoto, West African dwarf (WAD) and Sahel to give a total of 300 animals. .Nine body measurements were taken on these goats, which were used to estimate the ethnological indices and functional indices (as the zoometrical index) of the animals. There was significant effects $(p<0.05)$ of breeds on morphological traits of these animals. The functional and ethnological traits of these goat populations were significantly affected by breeds $(p<0.05)$ except pelvic and corporal. Based on the results of this study, Nigerian indigenous goats are medium-sized and their conformation corresponds to the meat type animals.

Keywords: Ethnology, functional, indigenous, population, zoometry

\section{Introduction}

Goat is one of the small ruminants that requires easy maintenance, it is prolific can produce twins, even triplets and can give birth three times in two years. Goat market prospects are also very promising particularly among rural women.In Africa, goat population is about 171 million and 22 million in Nigeria, this represents about $31 \%$ of the world total (FAO, 1991). In Nigeria, there are three indigenous breeds of goats these are: Red Sokoto, West African Dwarf, and Sahel (Osinowo et al., 1992). Ngere et al. (1984) reported that The Red Sokoto and Sahel breeds are predominantly found in Northern savannah and Sahel areas respectively, while the West African dwarf breed is common in the humid forest zone of southern Nigeria (Bayer, 1986). Nigerian indigenous goat breeds are primarily raised for meat; they have not been selected and improved for milk production.

The need for characterization of livestock breeds is a key to understanding their uniqueness and ability to thrive under various agrological climates. The phenotype of an animal is the resultant of the genetics and its blending with the environment where it thrives (Banerjee, 2015). Phenotypic characterization is therefore an important step in a conservation program, for breed identification and classification in ways that farming communities could be related (Dossa et al., 2007; Mwacharo et al., 2006). The global plan of action for animal genetic resources recognizes that a better understanding of the characteristics of livestock breeds is necessary for guiding decision making in the development of farms and breeding program (FAO, 2007). Linear body measurements have become very useful in livestock research as alternative body measurements. In Nigeria, several studies have been conducted on analysis of morphological studies for characterizing indigenous goat genetic resources (Fajemilehin and Salako 2008; Yakubu et al., 2010; Yakubu et al., 2011; Okpeku et al., 2011).

According to Salako (2006), indices estimated from various combinations of conventional and non-conventional body parameters not only provide superior guide to weight, but also served as indicators of 


\section{Zoometrical index analysis of Nigerian indigenous goat}

type and function in domestic animals. Mwacharo et al. (2006) also stated that, with the introduction of indices from body measurements, objective assessment of body conformation from the stand point of type may be relatively easier. Esquivelzeta et al. (2011) reported two types of indices which are ethnological and functional indices. Ethnological indices give general information about livestock breed characteristics in terms of describing structure and proportions which are morphological characteristics of an animal while functional indices provide information about the type, aptitude and production performance of the animal. The calculation and analysis of the different indices give room for morphological classification of livestock breed particularly the ruminants (Esquivelzeta et al., 2011). This study was conducted to describe the ethnological and functional indices of Nigerian indigenous breeds of goat.

\section{Materials and methods}

The study was conducted at three major small ruminant markets in Ibadan, Oyo state. These markets were Oranyan, Bodija and Akinyele. The study was also extended to households raising goats; these households were selected using snowball sampling technique. Nine body measurements were taken on 300 indigenous Nigerian breeds of goats (WAD, Red Sokoto and Sahel) of average ages of 25 - 30 months old using 100 individuals from each population. Meter rule was used to measure the height of the goats that is both the height at wither and at rump while other linear body measurements were taken using a measuring tape. The morphological measurements that were taken include body length, head length, head width, chest depth, chest width, chest girth, wither height, rump length and rump width. The morphological traits measured were used to estimate the functional and ethnological indices of individual animals as reported by

\section{Esquivelzeta et al. (2011):}

Cephalic $=$ Head Width $/$ Head Length $\times$ 100

Pelvic $=$ Rump Width / Rump Length $\times$ 100

Corporal $=$ Body Length $/$ Chest girth $\times$ 100

Body index $=$ Chest depth $/$ Wither height $\times 100$

Transversal pelvic $=$ Rump width $/$

Wither height $\times 100$

Longitudinal pelvic $=$ Rump length /

Wither height $\times 100$

Length $=$ Body length $/$ Wither height

Cephalic, pelvic and corporal are ethnological indices; body index, transverse pelvic, longitudinal pelvic and length are functional indices.

Data collected were subjected to PROCMEANS procedure of the SAS (2004) package.

\section{Results and discussions}

The result of the descriptive statistics of the morphological traits of the breeds of goat is presented in Table 2. The result showed relative high variability in terms of coefficient of variation (CV) ranging between $14.58 \%$ and $79.14 \%$ with the lowest obtained in longitudinal pelvic and body length and the highest $\mathrm{CV}$ obtained for body index. This implies variables with low CV have better accuracy of the test unlike variables with high $\mathrm{CV}$ as reported by (Acourele et al., 2001). Pares and Jordana, (2008) reported high CV in a morphometric study conducted for adult bovine. 


\section{Popoola and Adekanbi}

Table 1 : Descriptive statistics of morphological traits and zoometrical indices of indigenous goat populations

\begin{tabular}{llllll}
\hline Variable (cm) & Mean & Standard deviation & Variance & Range & Coefficient of variance \\
\hline Head width & 20.90 & 8.51 & 72.50 & 35.20 & 40.74 \\
Head length & 25.80 & 8.50 & 72.30 & 44.60 & 32.95 \\
Rump width & 16.64 & 3.74 & 14.01 & 20.20 & 22.50 \\
Rump length & 20.45 & 5.10 & 26.10 & 44.00 & 24.97 \\
Body length & 51.26 & 7.73 & 59.72 & 41.50 & 15.07 \\
Chest girth & 62.91 & 10.33 & 106.68 & 96.60 & 16.42 \\
Wither height & 55.55 & 9.12 & 83.22 & 53.00 & 16.42 \\
Transverse Pelvic & 0.30 & 0.06 & 0.00 & 0.46 & 21.28 \\
Longitudinal Pelvic & 0.93 & 0.14 & 0.02 & 1.08 & 14.58 \\
Length & 0.93 & 0.14 & 0.02 & 1.08 & 14.58 \\
Body Index & 87.09 & 68.15 & 4644.94 & 798.50 & 78.26 \\
Cephalic & 0.80 & 0.19 & 0.04 & 0.88 & 23.77 \\
Pelvic & 0.84 & 0.18 & 0.03 & 1.05 & 21.77 \\
Corporal & 0.87 & 0.68 & 0.46 & 7.99 & 18.26 \\
\hline
\end{tabular}

Table 2 shows the effects of breeds on morphological traits of the goats. There was significant effects $(p<0.05)$ of breeds on morphological traits of these animals. Red Sokoto goats had the widest head, Sahel goats had the widest rump; longest head, rump, body; highest value for chest girth and wither height. Generally, Sahel goat possesses the highest overall body linear measurements, followed by Red Sokoto and WAD displayed the lowest body linear measurements. This is an indication that Sahel goat is tallest and heaviest breed of goat in Nigeria compared to Red Sokoto and WAD. In previous studies, some body measurements such as wither height, body length, rump height, rump width and heart girth has been reported for WAD and Red Sokoto goats (Ozoje and Herbert, 1987;
Okepku et al., 2011), and other small ruminant species (Sowande and Sobola, 2010; Popoola, 2015). Similar and close values were reported by Okepku et al. (2011) for wither height, body length and heart girth for WAD and Red Sokoto goats. Dossa et al. (2007) reported higher average values of $56.57 \mathrm{~cm}$ and $79.23 \mathrm{~cm}$ for wither height and body length respectively for Benin goat populations; Edilberto et al. (2011) reported lower average values of head length, head width, rump width, rump length, but higher average values for body length, heart girth and wither height for Cuban Creole goat. Based on results obtained for these measurements on Nigerian indigenous goats, these goats may be considered medium sized as reported by Devendra and McLeroy (1982).

Table 2: Effects of breeds on morphological traits of indigenous goat populations

\begin{tabular}{lllll}
\hline Traits(cm) & Red Sokoto & Sahel & WAD & SEM( \pm ) \\
\hline Head width & $26.69^{\mathrm{a}}$ & $23.88^{\mathrm{b}}$ & $11.41^{\mathrm{c}}$ & 0.74 \\
Head length & $29.99^{\mathrm{b}}$ & $31.13^{\mathrm{a}}$ & $15.50^{\mathrm{c}}$ & 0.74 \\
Rump width & $16.15^{\mathrm{b}}$ & $19.11^{\mathrm{a}}$ & $14.85^{\mathrm{c}}$ & 0.32 \\
Rump length & $18.79^{\mathrm{c}}$ & $23.01^{\mathrm{a}}$ & $19.85^{\mathrm{b}}$ & 0.44 \\
Body length & $50.98^{\mathrm{b}}$ & $55.75^{\mathrm{a}}$ & $47.16^{\mathrm{c}}$ & 0.67 \\
Chest girth & $65.20^{\mathrm{b}}$ & $69.15^{\mathrm{a}}$ & $54.02^{\mathrm{c}}$ & 0.90 \\
Wither height & $57.72^{\mathrm{b}}$ & $61.39^{\mathrm{a}}$ & $47.29^{\mathrm{c}}$ & 0.79 \\
\hline
\end{tabular}




\section{Zoometrical index analysis of Nigerian indigenous goat}

Correlations between linear body measurements in indigenous goat populations are shown in Table 2 . Correlations between head width and head length $(r=0.81)$ recorded highest correlation value; there were also high correlations between body length and chest girth $(\mathrm{r}=0.71)$, head width and wither height $(r=0.61)$, head length and chest girth $(\mathrm{r}=0.67)$, head length and wither height $(\mathrm{r}=$ $0.69)$, rump width and body length $(r=$
0.61). Head length was less correlated with rump length $(\mathrm{r}=0.05)$. The positive correlations between these morphological traits obtained in the present study indicate that an increase in any one of the body measurement would result in a corresponding increase in the other traits. Similar results of phenotypic correlations among body measurements of goats have been reported in earlier studies (Yakubu 2009; Sowande et al., 2010; Nafti et al., 2014).

Table 3: Phenotypic correlation coefficients of morphological traits of indigenous goat populations

\begin{tabular}{llllllll}
\hline & $\begin{array}{l}\text { Head } \\
\text { width }\end{array}$ & $\begin{array}{l}\text { Head } \\
\text { length }\end{array}$ & $\begin{array}{l}\text { Rump } \\
\text { width }\end{array}$ & $\begin{array}{l}\text { Rump } \\
\text { length }\end{array}$ & $\begin{array}{l}\text { Body } \\
\text { length }\end{array}$ & $\begin{array}{l}\text { Chest } \\
\text { girth }\end{array}$ & $\begin{array}{l}\text { Wither } \\
\text { height }\end{array}$ \\
\hline & & & & & & & \\
Head width & 0.81 & 0.18 & 0.05 & 0.37 & 0.57 & 0.61 \\
Head length & & 0.40 & 0.24 & 0.49 & 0.67 & 0.69 \\
Rump width & & & 0.46 & 0.61 & 0.55 & 0.47 \\
Rump length & & & & 0.38 & 0.26 & 0.32 \\
Body length & & & & & 0.71 & 0.56 \\
Chest girth & & & & & & & 0.68 \\
Wither height & & & & & & & \\
\hline
\end{tabular}

The functional and ethnological traits of Nigerian indigenous goat populations are presented in Table 4. Functional and ethnological traits of Nigerian indigenous goat populations were significantly affected by breeds $(\mathrm{p}<0.05)$ except pelvic and corporal which are ethological traits. On the bases of functional indices which provide information about the type, aptitude and production performance of an animal; WAD goats had highest transverse pelvic, longitudinal pelvic, length, body index, corporal and head index compared to Sahel and Red Sokoto goats. The transversal pelvic and longitudinal pelvic indexes also provided information about the aptitude of the animal, supporting the WAD as the best breed for meat production when compared to other breeds. Similar result was reported by Salako (2006) for a study on sheep. The length suggest that these breeds of goat to be long-shaped with WAD being the longest breed, this reinforces the results obtained for calculation of body index which shows WAD goats to be longiline having the body index ((Body length / Heart girth) higher than 90, Red Sokoto and Sahel goats are brevigline with body index value of less than 85 (Edilberto et al., 2011). On the bases of ethnological indices which give general information in terms of describing structure and proportions of animal; the cephalic index for Red Sokoto goat is 0.9 indicating that the goat is brachycephalic that is short-headed because the width of the head predominated over the length.; the cephalic index for Sahel and WAD are 0.78 and 0.71 respectively, indicating that these goats are mesaticephalic (medium-headed) and dolicocephalic (long-headed - because the length of the head predominated over the width) respectively. Edilberto et al. (2011) reported that Cuban Creole goats and their crossbreeds are brachycephalic. 
Similar finding was reported by Popoola (2015) for WAD sheep. The pelvic and corporal indices show indicates the rump length predominating in relation to its amplitude.

Table 6: $E$ ffects of breeds on ethnological and functional traits of Nigerian indigenous goat populations

\begin{tabular}{lllll}
\hline Traits $(\mathbf{c m})$ & Red Sokoto & Sahel & WAD & SEM( $( \pm)$ \\
\hline Transverse Pelvic & $0.28^{\mathrm{c}}$ & $0.31^{\mathrm{b}}$ & $0.32^{\mathrm{a}}$ & 0.01 \\
Longitudinal Pelvic & $0.88^{\mathrm{c}}$ & $0.91^{\mathrm{b}}$ & $1.01^{\mathrm{a}}$ & 0.01 \\
Length & $0.88^{\mathrm{c}}$ & $0.91^{\mathrm{b}}$ & $1.01^{\mathrm{a}}$ & 0.01 \\
Body Index & $78.14^{\mathrm{c}}$ & $80.75^{\mathrm{b}}$ & $103.03^{\mathrm{a}}$ & 5.91 \\
Cephalic & $0.90 \mathrm{a}$ & $0.78 \mathrm{~b}$ & $0.71 \mathrm{c}$ & 0.02 \\
Pelvic & 0.87 & 0.86 & 0.78 & 0.02 \\
Corporal & 0.78 & 0.81 & 1.03 & 0.06 \\
\hline
\end{tabular}

${ }^{a, b, c}$ means of different superscripts along the same row are significantly different $(\mathrm{P}<0.05)$

\section{Conclusion}

Based on the results of this study it is concluded that Nigerian indigenous goats are medium-sized animals, their conformation corresponds to the meat type animal. Further studies can be conducted using more structural indices that will reveal potentials of these goats in terms of type and production performance which will serve the purpose for designing appropriate conservation, breeding, selection and sustainable utilization strategies for Nigerian indigenous goats.

\section{References}

Acourene, S., Belguedj, M., Tam, M. and Taleb, B. 2001. Caractérisation, évaluation de la qualité de datte et identification des cultivars de palmier dattier de la région des Zibans. La Recherche Agronomique, INRA Algérie no 8: 19-39.In: Nafti M., Khaldi Z. and Haddad B. (2014). Multivariate characterization of morphological traits in local Tunisian oases goats. Anim. Gen. Res.55: 29-38

Banerjee, S. 2015. Morphometrical and production traits of Bengal sheep in West Bengal, India Animal Genetic
Resources, 57, 57-71.

Bayer, W. 1986. Traditional Small Ruminant Production in the Sub humid Zone of Nigeria. Proceedings of the second ILCA / NAPRI Symposium held in Kaduna, Nigeria, 29th Oct. - 2nd Nov., 1986.Pp. 141 - 166.

Devendra, C. and McLeroy, G. B. 1982. Goat and sheep production in the tropics. Intermediate Tropical Agriculture Series. Longman Group, U.K. 271 pp

Dossa, L. H., Wollny, C., Gauly, M. 2007. Spatial variation in goat populations from Benin as revealed by multivariate analysis of morphological traits. Small Rumin. Res. 73, 150-159.

Edilberto, C., Fernando, M., Francisco, V., Samuel, R. P., Eliecer, P. and Concepta，M . 2011 . Morphological measurements and body indices for Cuban Creole goats and their crossbreds. Revista Brasileira de Zootecnia, 40(8): 1671-1679.

Esquivelzeta, C., Fina, M., Bach, R., Madruga, C., Caja, G., Casellas, J. and Piedrafita J. 2011. 


\section{Zoometrical index analysis of Nigerian indigenous goat}

Morphological analysis and subpopulation characterization of Repollesa sheep breed. Animal Genetics Resources Journal 49: 91

Fajemilehin, O. K. S. and Salako, A. E. 2008. Body measurements characteristics of the West African Dwarf (WAD) goats in deciduous forest zone of southwestern Nigeria. Afr. J. Biotechnol. 7, 2521-2526.

FAO. 2007. Global Plan of Action for Animal Genetic Resources and the Interlaken Declaration. available at http://www.fao.org/ docrep/010/a1404e/a1404e00.HT $M$.

FAO. 1991. Livestock and Livestock Products. Quarterly Bulletin of Statistics, Food and Agricultural Organization, FAO, Rome, Italy. 4(3): 39 .

Mwacharo, J. M., Jianlin, H. and Amano T. 2006. Native African goat: valuable genetics resources for future breeding improvement. The Journal of Animal Genetics (Japan) 34:63-69

Nafti, M. Khaldi, Z. and Haddad, B. 2014 . M u ltivariate characterization of morphological traits in local Tunisian oases goats. Animal Genetic Resources, 55, 29-38

Ngere, L. O., Adu, I. F. and Okubanjo, I. O. 1984. The Indigenous goat of Nigeria. FAO/ UNEP Animal Genetic Resource Information. Food and Agricultural Organization of the United Nations, Rome, Italy. 3:1-9.

Okpeku, M., Yakubu, A., Olusola, P., Ozoje, O. M., Ikeobi, C. O., Adebambo, O. A. and Imumorin,
I G. 2011. Application of multivariate principal component analysis to morphological characterization of indigenous goats in Southern Nigeria. Acta Agriculturea Slovenica. 98:101109.

Osinowo, O. A., Olorunju, S. A. S., Otehere, E. O. and Arigi, L. A. 1992. Relationship between Chest girth and live weight in Yankasa Sheep and Red Sokoto Goats. Journal of Animal Production Research 12 (2): 69-71.

Ozoje, M. O. and Herbert, U. 1997. Linear measurements in West African Dwarf goats and West African Dwarf X Red Sokoto goats. Nigerian Journal of Animal Production 24: 13-19

Pares, P. M. and Jordana, J. 2008. Zoometric measurements of cephalic conformation in adult bovine males and females (Bos Taurus). Veterinarija ir Zootechnika, 43 (65): 73-76.

Popoola, M. A. 2015. Zootechnical Index Analysis of West African Dwarf Rams in Southwestern Nigeria. Agricultura Tropica ET Subtropica. 48 (1): 138-143.

Salako, A. E. 2006. Application of morphological indices in the assessment of type and function in sheep. International Journal of Morphology 24: 13-18.

SAS, 2004. Statistical Analysis System. Guide for personal computer. Release 8.I SAP Institute.Inc. Cary. NC USA

Sowande, O. S., Oyewale, B. F. and Iyasere, O. S. 2010. Age- and sexdependent regression models for predicting the live weight of West African Dwarf goat from 
body measurements, TroAnim. Health Prod., 42: 969-975.

Sowande, O. S. and Sobola, O. S. 2008. Body measurements of West African Dwarf sheep as parameters for estimation of live weight. Trop. Anim.Health Prod. 40, 433-439

Yakubu, A. 2009. Principal component analysis of the morphostructural indices of White Fulani cattle. Trakia J. Sci., 7: 67-73.
Yakubu, A., Salako A. E., Imumorin, I. G., Ige, A. O. and Akinyemi, M. O. 2010. Discriminant analysis of morphometric differentiation in the West African Dwarf and Red Sokoto goats. S. Afr. J. Anim. sci. vol. 40 n. 4

Yakubu, A., Salako, A. E. and Abdullah, A. R. 2011. Varimax rotated principal component analysis of the zoometrical traits of Uda sheep. Archivos de Zootecnia, 60 (231): 813-816

Received: $20^{\text {th }}$ August, 2016 Accepted: $17^{\text {th }}$ March, 2017 